\title{
POSTSYNAPTIC POTENTIALS IN TOAD'S SPINAL MOTONEURONS DUE TO MUSCLE AFFERENT VOLLEYS
}

\author{
Yasushi FUKAMI* \\ Department of Physiology, Faculty of Medicine, Kyoto University, Kyoto
}

\begin{abstract}
Although some investigators are dubious of a direct connection between the dorsal root fibers and the motoneurons in frog spinal cord ${ }^{21)}$, evidences for the monosynaptic connection between them have recently been presented by ARAKI ${ }^{3)}$, BROOKHART and FADIGA ${ }^{7)}$ and FADIGA and BRoOKHART ${ }^{16)}$ with toad's and frog's spinal cord. In their experiments a single orthodromic stimulus delivered to a dorsal root set up a monosynaptic excitatory postsynaptic potential (EPSP) which, however, never reached by itself motoneuron threshold, unless either the potential was augmented by summation of plurisynaptic EPSP's, or the threshold was lowered by cathodal polarization.

As is widely known, the monosynaptic reflex is more pronounced in antigravity muscles which support the animal body resisting the action of gravity. In this sense, it might be expected that, in frogs or toads, the monosynaptic reflex would be more developed in the muscles of forelimbs than in those of hindilimbs. In the present study, therefore, an attempt was made to explore the monosynaptic reflex in the rostral segments of toad's spinal cord which innervate forelimb muscles. Along with EPSP, inhibitory postsynaptic potential (IPSP) elicited by volleys in muscle afferents was the subject of the present study, on which only little has so far been known.
\end{abstract}

\section{METHODS}

The experiments were performed on toad's spinal cord in situ. Curarization of the animal was avoided as much as possible, since it seemed to impair lively condition of the spinal cord. After the rostral segments of the cord had been exposed by laminectomy and the dura as well as the arachnoid had been removed carefully, the II and IV ventral and dorsal roots and the III ventral root were severed with sharp scissors. The surface of the cord was usually covered with RiNGER's solution or with liquid paraffin. The nerve branches to triceps muscle (extensor) and to biceps muscle (flexor) of the forelimb were exposed with their peripheral ends sectioned. The nerve branches to other muscles were hardly accessible because of their brevity.

Bipolar silver electrodes were available for orthodromic stimulation of these prepared nerve branches. Afferent fibers from these muscles usually enter into spinal

Received for publication April 18, 1961

* 深見 安 
cord through the III dorsal root, from which afferent volleys were recorded with a monopolar silver electrode near its entrance to the cord. The animal was firmly fixed to a metal frame specially designed in this laboratory.

The recording system was composed of a balanced D.C. amplifier with cathode follower input stage, R-C coupled amplifier (time constant: $0.5 \mathrm{sec}$ ) and a dual-beam oscilloscope. The R-C coupled amplifier was available for recording dorsal root volleys.

With the aid of a micromanipulator a glass micropipette filled with $0.5 \mathrm{M}-\mathrm{K}_{2} \mathrm{SO}_{4}$ or $3 \mathrm{M}-\mathrm{KCl}$ solution was inserted from the dorsal surface of the cord at the levei between the II and the IV spinal segments from which pia had carefully been removed with fine scissors. The indifferent electrode was attached to the metal frame.

The equilibrium potential of IPSP was measured by sending a square pulse of long duration supplied by an electronic stimulator with an isolation unit to the bridge circuit described by ARAKI and OTANI ${ }^{2)}$. Micropipettes filled with 2 M-potassium citrate were used in this case for recording intracellular potentials.

All experiments were carried out at room temperature, $13 \sim 24^{\circ} \mathrm{C}$.

\section{RESULTS}

I. Response of motoneurons to stimulation of muscle afferent. To a single shock delivered to the ipsilateral triceps nerve some motoneurons penetrated with a micropipette responded with an EPSP at an intraspinal latency of 1.5 to 2.0 msec. The latent time seems to indicate monosynaptic connection between the primary afferent and the motoneuron (cf. 3, 7, 16). FIG. 1 A shows a typical example of EPSP which has both rising and falling phases of simple contour indicating its purely monosynaptic nature. A slight increase in the stimulus intensity

A B

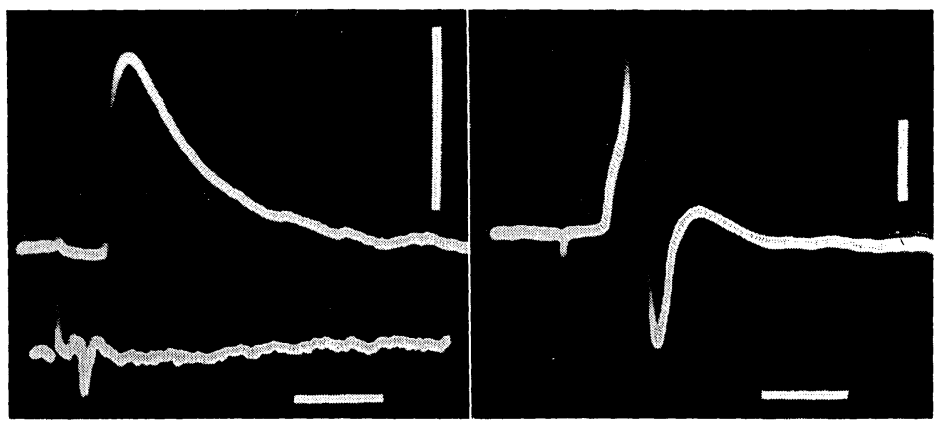

FIG. 1. Monosynaptic EPSP and spike discharge in a motoneuron in the rostral part of toad spinal cord.

A : a typical monosynaptic EPSP evoked by stimulating ipsilateral nerve branch to triceps muscle. Lower trace shows afferent volley recorded near entry of III dorsal root into spinal cord. Negativity downward.

B: the same motoneuron as in A. Spike discharge from the monosynaptic EPSP obtained by slightly increased stimulus strength. Time : 5 msec. Voltage scales: $5 \mathrm{mV}$. 
brought about a spike discharge from such a monosynaptic EPSP (FIG. 1 B). The muscle innervated by the explored motoneuron was not identified by antidromic activation of the motoneuron, because the ventral root had been sectioned before the penetration of motoneuron.

It was rather infrequent to penetrate a motoneuron in which a stimulus to a certain muscle nerve elicited a monosynaptic EPSP large enough to fire the cell. Results obtained from motoneurons on random insertion of the micropipette were rather varying. Among them was a hyperpolarizing PSP, which sometimes appeared preceded by depolarization of small amplitude (FIG. 2 A, B). The hyperpolarizing PSP is considered to be an IPSP similar to that of the cat spinal cord because of its reversal potential comparable to that of the latter (see below). In the same motoneuron, the response to stimulation of the triceps nerve was as a rule different from that of biceps nerve stimulation, in some cases in the sign of PSP's, in others only in the latent time, responding equally with EPSP's to either stimulation. Motoneurons responding with monosynaptic EPSP to both of triceps and biceps nerve stimulations have never been encountered. Many motoneurons did not show any monosynaptic PSP to either stimulation. When the monosynaptic response was absent, there were almost invariably responses of supposedly disynaptic nature, i.e., EPSP's or insignificant undulatory changes of membrane potential starting at an intraspinal delay of about $3.0 \mathrm{msec}$. (Fig.

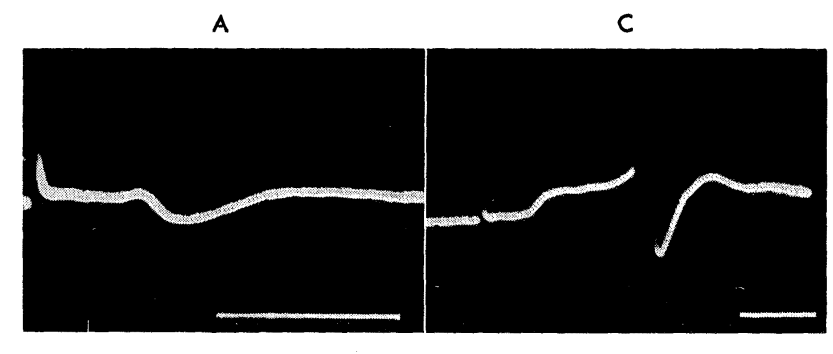

B

D

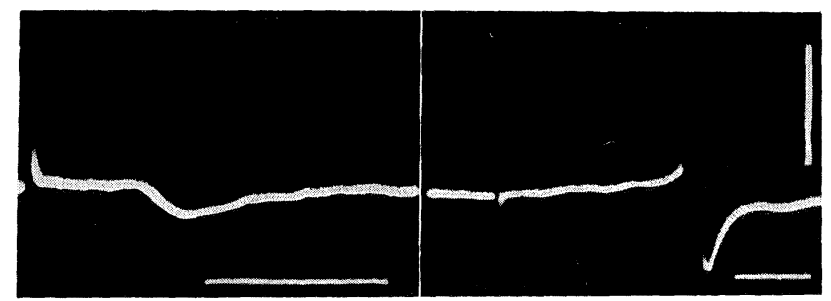

FIG. 2. Various responses of motoneurons to single volleys in ipsilateral muscle afferent. Each record was taken from different motoneuron.

A and B: IPSP's which are most likely disynaptic, with and without preceding depolarization. C: EPSP at disynaptic delay. D: insignificant undulatory changes in the membrane potential leading to a spike discharge. Time : $10 \mathrm{msec}$. Voltage calibration : $10 \mathrm{mV}$. 
2 C, D). Sometimes a spike discharge occurred at a much longer delay.

II. Intraspinal latency of PSP's. Time intervals between the arrival of afferent impulses at the spinal cord and the onset of PSP's were measured at room temperatures ranging $16 \sim 24^{\circ} \mathrm{C}$. As shown in TABLE I, the shortest group of intraspinal latencies of EPSP was $1.54 \pm 0.042 \mathrm{msec} .(\mathrm{M} \pm$ S.E. $)$ and that of IPSP was $3.06 \pm 0.113 \mathrm{msec}$. at room temperatures between $22 \sim 24^{\circ} \mathrm{C}$. As has been pointed out by the previous authors ${ }^{1,3,16}$, the latency seems to indicate that the EPSP's in this group were set up through the monosynaptic pathway. On the other hand, since the afferent fibers from triceps and biceps were equally demonstrated to enter into the spinal cord through the III dorsal root, and therefore the intraspinal distances traveled by the impulses from both nerve branches were most likeiy the same, the latent time of IPSP, which was approximately twice as long as that of EPSP, seems to indicate an extra synaptic delay involved in the inhibitory pathway.

TABLE I

Intraspinal latencies of monosynaptic EPSP and disynaptic IPSP

\begin{tabular}{cccccc}
\hline & \multicolumn{2}{c}{ EPSP } & & \multicolumn{2}{c}{ IPSP } \\
\cline { 2 - 3 } & $\begin{array}{c}\text { Latency } \\
(\text { msec. })\end{array}$ & $\begin{array}{c}\text { Room Temp. } \\
\left({ }^{\circ} \mathrm{C}\right)\end{array}$ & & $\begin{array}{c}\text { Latency } \\
(\text { msec. })\end{array}$ & $\begin{array}{c}\text { Room Temp. } \\
\left({ }^{\circ} \mathrm{C}\right)\end{array}$ \\
\hline$(1)$ & 1.7 & 24 & $(1)$ & 3.1 & 24 \\
$(2)$ & 1.5 & 24 & $(2)$ & 3.0 & 24 \\
$(3)$ & 1.5 & 24 & $(3)$ & 2.8 & 24 \\
$(4)$ & 1.5 & 23 & $(4)$ & 3.0 & 24 \\
$(5)$ & 1.5 & 23 & $(5)$ & 3.1 & 23 \\
$(6)$ & 1.6 & 23 & $(6)$ & 3.0 & 22 \\
$(7)$ & 1.5 & 22 & $(7)$ & 3.2 & 22 \\
& & & $(8)$ & 3.0 & 22 \\
& & & $(9)$ & 3.2 & 22 \\
$(8)$ & 2.0 & & $(10)$ & 3.0 & 22 \\
$(9)$ & 1.8 & 16 & $(11)$ & 4.0 & 16 \\
\hline
\end{tabular}

Mean $\left(22^{\circ} \mathrm{C} \sim 24^{\circ} \mathrm{C}\right): 1.54 \pm 0.042 \mathrm{msec} . \quad$ Mean $\left(22^{\circ} \mathrm{C} \sim 24^{\circ} \mathrm{C}\right): 3.06 \pm 0.113 \mathrm{msec}$. $\mathrm{Q}_{10}=1.71$

TABLE I also shows that the higher the room temperature the shorter the intraspinal latency of PSP's. $\mathrm{Q}_{10}$ for the intraspinal latency of monosynaptic EPSP's was roughly estimated to be about 1.71 from the values shown in TABLE I. The intraspinal latency at $37^{\circ} \mathrm{C}$ was also calculated by use of this $\mathrm{Q}_{10}$ value and it was revealed that the calculated latency is nearly equal to that of monosynaptic EPSP in cat's spinal motoneurons ${ }^{10}$.

III. The time constant of decay of PSP's. The recording of typical monosynaptic EPSP and most probably disynaptic IPSP in toad's spinal motoneurons in 


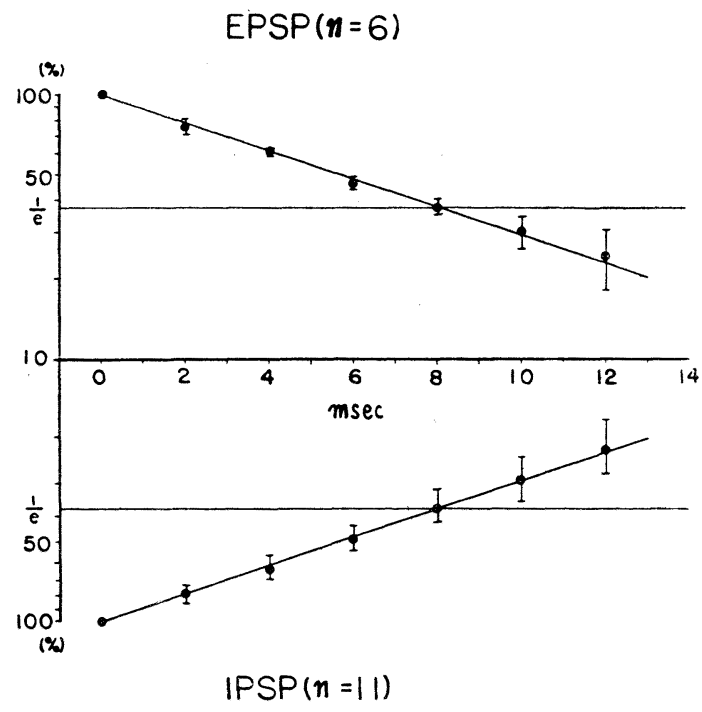

FIG. 3. Time course of decay of typical monosynaptic EPSP's and disynaptic IPSP's.

Ordinates: size of PSP's at varying moments of decay expressed as percentages of the peak value (logarithmic scale). Means and standard errors (vertical bars) calculated from 6 EPSP's and 11 IPSP's.

Abscissae: time after the peak of PSP's.

situ was sometimes disturbed by spontaneous firing of the motoneuron and also by random synaptic activities which distorted the time course of their decay. The time course of decay seemingly not contaminated with such activities is shown in FIG. 3, in which sizes of PSP's expressed as percentages of their peak values are plotted against time after the peak on a semilogarithmic scale. The vertical bar on each plot shows the range of standard error. From FIG. 3 it is clear that there is no marked difference in the time constant of decay between EPSP $(8.0 \pm 0.6 \mathrm{msec}$. $)$ and IPSP $(8.0 \pm 0.97 \mathrm{msec}$. $)$. These values seem somewhat longer than the time constant of motoneuron membrane measured by the direct method $^{2,3)}$ (Mean about $4.5 \mathrm{msec}$, ranging from 1.5 to $8 \mathrm{msec}$.).

The rise times of monosynaptic EPSP and disynaptic IPSP were also measured to be $2.10 \pm 0.26 \mathrm{msec}$. and $2.15 \pm 0.211 \mathrm{msec}$. respectively $(\mathrm{M} \pm$ S.E. $n=10$ in both cases). The whole time course of monosynaptic EPSP is therefore practically a mirror image of that of disynaptic IPSP differing only in its shorter central latency.

IV. The equilibrium potential of IPSP. Although the presence of IPSP has been demonstrated in lumbar motoneurons of toad's spinal cord ${ }^{1,19)}$, its equilibrium potential has not yet been reported. In the present experiment an attempt 


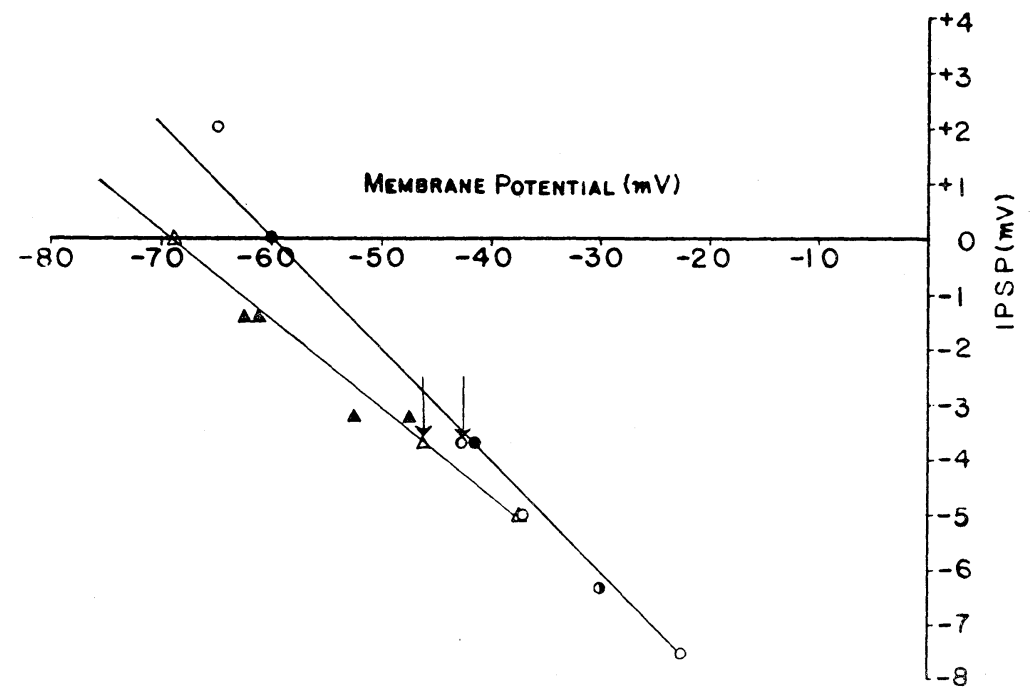

FIG. 4. Peak amplitudes of IPSP's plotted as ordinates against initial membrane potentials as abscissae. Two examples (circles and triangles) are shown. Hyperpolarizing and depolarizing IPSP's are plotted respectively as negative and positive voltages.

Open circles and triangles: values obtained when membrane was progressively hyperpolarized.

Filled circles and triangles: values with the membrane potentials changed in reverse direction.

Arrows show respective normal resting potentials.

was made to determine the equilibrium potential by sending rectangular current pulses of about $0.5 \mathrm{sec}$. duration and of varying intensities to the motoneuron membrane through an intracellular electrode in a bridge circuit.

Two examples of the results are shown in Fig. 4, in which the membrane potentials are plotted against the sizes of IPSP's. FIG. 4 shows almost linear relationship between these two variables. The respective equilibrium potentials were found to be $-60 \mathrm{mV}$ and $-69 \mathrm{mV}$, which were more hyperpolarized by $10 \sim 20 \mathrm{mV}$ than the normal resting membrane potentials.

\section{DISCUSSION}

The presence of monosynaptic connection between the primary afferent and a motoneuron have already been reported by several investigators ${ }^{1,3,7,16)}$, in toad or frog spinal cord, in spite of the contradictory report of histological investigation by LIU and CHAMBERs ${ }^{21)}$. In the present study it was confirmed that the afferent fibers in question are of muscular origin. Although the muscle supplied by the tested motoneuron was not experimentally identified, it seems reasonable to presume that the observed monosynaptic pathway is concerned 
with the myotatic reflex well-known in mammals. Judging from the relative paucity of monosynaptic EPSP, the monosynaptic reflex is still admittedly only poorly developed in toad spinal cord even in its rostral part. With almost equal difficulty were the motoneurons fired through the monosynaptic pathway, whether triceps or biceps nerve was stimulated.

The time constant of decay of EPSP in toad motoneuron has never been reported, because in the reports so far available orthodromic stimuli were always given to a dorsal root, which is inadequate to produce exclusively monosynaptic EPSP. Working with isolated frog spinal cords and using pentobarbital to silence internuncial discharge, FADIGA and BROOKHART ${ }^{16)}$ measured the time constant of decay of EPSP produced by a dorsal root stimulation to be about $10 \mathrm{msec}$. Hence the values obtained here are not significantly different from that of frog motoneurons.

The presence of IPSP in the toad spinal cord has often been inferred ${ }^{1,19,25)}$. Viewed from the present knowledge, also the ventral root electrotonic potentials reported by IWATA and ARAKI ${ }^{18)}$, which appeared as a sharp positive deflection when the cord surface was made negative in regard to the ventral root, can be regarded as an indirect evidence for the presence of IPSP in toads. Here again, however, the present study revealed that at least some of the IPSP's resulted from impulses in the muscle afferent. It also revealed that IPSP decayed as fast as the monosynaptic EPSP did, though, in the cat spinal cord, precise measurements show that the time constant of decay of "direct" IPSP is shorter than that of monosynaptic EPSP,10,12,15).

With cat's lumbar cord it was first found by ECCLES, FATT and LANDGREN ${ }^{14)}$ with intracellular electrodes that the central latency of 'direct' IPSP was longer than that of monosynaptic EPSP. This important finding was explained by interposing one interneuron in the central pathway of 'direct inhibition' which had been believed to be monosynaptic ${ }^{5,6,13,20,22)}$. The longer latency of IPSP was found also in sacral segments by CURTIS, KRnJevic and Miledi ${ }^{11)}$ and FRANK and SPRAGUE ${ }^{17)}$, although reaffirmation of the earlier hypothesis of direct inhibitory path has often been made ${ }^{23,24,26)}$. Recently the problem has more precisely been studied by ARAKI, ECCLES and $\mathrm{ITO}^{4)}$. In conformity with the finding of Eccles et al. ${ }^{14)}$ in cats, the results shown in TABLE I indicate an extra synaptic delay involved in the latency of IPSP also in the amphibian spinal cord.

The equilibrium potential of IPSP was found to be $-60 \sim-69 \mathrm{mV}$ and $10 \sim 20 \mathrm{mV}$ more hyperpolarized than the normal resting potential. It was also noticed that, with the microelectrodes filled with $\mathrm{KCl}$, a hyperpolarizing potential became progressively less conspicuous with the lapse of time after impalement. It seems permissible, therefore, to assume that the generating mechanisms of IPSP in spinal motoneurons are the same both in cats and toads. 


\section{SUMMARY}

1. Synaptic activities in the rostral segments (II, III and IV) of toad's spinal cord in situ were investigated by recording intracellular potentials of motoneurons.

2. In response to an afferent volley in the ipsilateral nerve branch to triceps or biceps muscle there appeared in some motoneurons a monosynaptic EPSP, from which a spike discharge occurred in some instances, without any superposition of delayed PSP's. Some other motoneurons responded with a typical IPSP, while the rest with EPSP's or insignificant undulatory changes of membrane potential, all starting at longer latencies than the monosynaptic delay.

3. Measured from the arrival of afferent volleys at the surface of the cord, the latencies of the monosynaptic EPSP's and the earliest IPSP's were 1.54 \pm 0.042 msec. and $3.06 \pm 0.113 \mathrm{msec}$. respectively $\left(22 \sim 24^{\circ} \mathrm{C}\right)$. The latter is reasonably regarded to involve an extra synaptic delay.

4. EPSP and IPSP were nearly equal in their time course. The rise time and the time constant of decay of EPSP are $2.10 \pm 0.026 \mathrm{msec}$. and $8.0 \pm 0.6 \mathrm{msec}$, respectively, and those of IPSP are $2.15 \pm 0.211 \mathrm{msec}$. and $8.0 \pm 0.97 \mathrm{msec}$. $\left(22 \sim 24^{\circ} \mathrm{C}\right)$.

5. Observations were also made on the equilibrium potential of IPSP which was found to be 10 to $20 \mathrm{mV}$ more hyperpolarized than the normal resting potential.

Thanks are due to Professor T. OTANI for his criticism and encouragement throughout this experiments and the preparation of this paper.

\section{REFERENCES}

1) ARAki, T., OtANI, T. AND FURUKAwA, T. The electrical activities of single motoneurons in toad's spinal cord, recorded with intracellular electrodes. Jap. J. Physiol. 3: 254-267, 1953.

2) ARAKI, T. AND OtANI, T. Response of single motoneurons to direct stimulation in toad's spinal cord. J. Neurophysiol. 18: 472-485, 1955.

3) ARAKI, T. Effects of electrotonus on the electrical activities of spinal motoneurons of the toad. Jap. J. Physiol. 10: 518-532, 1960.

4) ARAKI, T., ECCLES, J. C. AND ITO, M. Correlation of the inhibitory postsynaptic potential of motoneurones with the latency and time course of inhibition of monosynaptic reflexes. J. Physiol. 154: 354-377, 1960.

5) Bradly, K., EAston, D. M. AND ECCLES, J. C. An investigation of primary or direct inhibition. J. Physiol. 122: 474-488, 1953.

6) Brock, L. G., Coombs, J. S. ANd Eccles, J. C. The nature of the monosynaptic excitatory and inhibitory processes in the spinal cord. Proc. Roy. Soc., B. 140: 170-176, 1952.

7) Brookhart, J. M. AND Fadiga, E. Potential fields initiated during monosynaptic activation of frog motoneurones. J. Physiol. 150: 633-655, 1960.

8) Coombs, J. S., Curtis, D. R. AND ECcles, J. C. Excitatory synaptic action in motoneurones. J. Physiol. 130: 374-395, 1955. 
9) Coombs, J. S., CuRtis, D. R. And Eccles, J. C. Time courses of motoneuronal responses. Nature, 178: 1049-1050, 1956.

10) Coombs, J. S., Curtis, D. R. ANd Eccles, J. C. The electrical constants of the motoneurone membrane. J. Physiol. 145: 505-528, 1959.

11) CuRtis, D. R., KRnJevic, K. AND MILEDI, R. Crossed inhibition of sacral motoneurones. J. Neurophysiol. 21: 319-326, 1958.

12) CuRtis, D. R. AND ECCLES, J. C. The time courses of excitatory and inhibitory synaptic actions. J. Physiol. 145: 529-546, 1959.

13) ECCLES, J. C. The Neurophysiological Basis of Mind. Oxford, Clarendon Press, 1953.

14) Eccles, J. C., FATt, P. AND Landgren, S. The central pathway for the direct inhibitory action of impulses in the largest afferent fibers of muscle. J. Neurophysiol. 19: 75-98, 1956.

15) ECCLES, J. C. The Physiology of Nerve Cells. Baltimore, The Johns Hopkins Press, 1957.

16) FAdiga, E. AND BRoOKHART, J. M. Monosynaptic activation of different portions of the motoneuron membrane. Amer. J. Physiol. 198: 693-703, 1960.

17) Frank, K. AND Sprague, J. M. Direct contralateral inhibition in the lower sacral spinal cord. Exp. Neurol. 1: 28-43, 1959.

18) IWATA, S. AND ARAKI, T. On the nature of positive waves in ventral root potential. Jap. J. Physiol. 3: 200-210, 1953.

19) Kuno, M. Effects of strychnine on the intracellular potentials of spinal motoneurones of the toad. Jap. J. Physiol. 7: 42-50, 1957.

20) LAPORTE, Y. AND LLOYD, D. P. C. Nature and significance of the reflex connections established by large afferent fibres of muscle origin. Amer. J. Physiol. 169: 609-621, 1952.

21) LiU, C. N. AND Chambers, W. W. Experimental study of anatomical organization of frog's spinal cord. Anat. Rec. 127: 326, 1957.

22) Lloyd, D. P. C. Facilitation and inhibition of spinal motoneurons. J. Neurophysiol. 9: 421-438, 1946.

23) LLOYD, D. P. C. AND WILSON, V. J. Functional organization of central excitatory and inhibitory latencies in monosynaptic reflex systems. J. Gen. Physiol. 42: 1219-1231, 1959.

24) Lloyd, D. P. C. Spinal mechanisms involved in somatic activities. In Field's "Handbook of Physiology" Sect. 1, Vol. II. 929-949, 1960.

25) WASHIZU, Y. The effect of TEA on the electrical activities of spinal motoneurons. Jap. J. Physiol. 9: 311-321, 1959.

26) Wilson, V. J. AND Lloyd, D. P. C. Bilateral spinal excitatory and inhibitory actions. Am. J. Physiol. 187: 641, 1956. 